several symposia, and currently serves as the faculty advisor for the local MRS Student Chapter.

\section{Andrea M. Hodge (2015)}

Hodge is a professor and the Philip and Cayley MacDonald Early Career Chair in the Aerospace and Mechanical Engineering Department with a joint appointment at the Mork Family Department of Chemical Engineering and Materials Science at the University of Southern California. Her research interests range from processing of nanocrystalline and nanoporous materials to nanomechanics of metals and biomaterials. For MRS, Hodge has served as a symposium organizer and as a chair of the 2011 International Materials Research Congress. She is currently a principal editor of the Journal of Materials Research.

\section{Oliver Kraft (2013)}

Kraft is Director at the Institute for Applied Materials and Robert Bosch Professor for Nanostructured Functional Materials at the Karlsruhe Institute of Technology. His research interests range from the mechanical behavior of advanced structural and functional materials to the reliability of microelectronic and microelectromechanical systems devices. For MRS, he served as a Chair of the 2005 MRS Spring Meeting and he was a member of the Program Development Subcommittee.
Hideki Matsumura (2013)

Matsumura is Professor and Immediate Past Dean of the School of Materials Science and special advisor to the president at Japan Advanced Institute of Science and Technology. His research focus is in the field of thin-film technology, CatCVD, to prepare device quality thin-film materials. Matsumura has been active in MRS mainly in the field of amorphous materials, where he has served as a symposium organizer.

\section{Fiona C. Meldrum (2015)}

Meldrum holds a chair in Inorganic Chemistry at the University of Leeds, where her research centers on bioinspired materials chemistry. For MRS, she has served as a symposium organizer, a cochair for the 2013 International Materials Research Congress, and as a Volume Organizer for MRS Bulletin, where she currently serves on the Editorial Board.

\section{Eric A. Stach (2015)}

Stach is the Group Leader for the Electron Microscopy Group at the Brookhaven National Laboratory's Center for Functional Nanomaterials, where he focuses on real-time studies of working catalysts and the nucleation and growth of nanostructure materials. He is also the Chief Technology Officer for Hummingbird Scientific, which he co-founded in 2004. Stach has served as a guest editor for MRS Bulletin, a symposium organiz- er, and as a chair for the 2012 MRS Fall Meeting. He is currently a principal editor of the Journal of Materials Research.

\section{Stephen Streiffer (2014)}

Streiffer is currently Deputy Associate Laboratory Director for the Physical Sciences and Engineering Directorate (PSE) at Argonne National Laboratory. His scientific expertise is in nanostructured oxides and nitrides and in structural characterization of materials. For MRS, he served as a Volume Organizer for $M R S$ Bulletin, as a symposium organizer, and as a member of the Public Outreach Committee that developed the traveling exhibition Strange Matter and the PBS NOVA four-part series Making Stuff.

\section{Susan E. Trolier-McKinstry (2013)}

Trolier-McKinstry is a Professor of Ceramic Science and Engineering and Director of the W. M. Keck Smart Materials Integration Laboratory at The Pennsylvania State University. Her research interests include ferroelectric thin films for dielectric and piezoelectric applications, microelectromechanical systems, and the development of texture in bulk ceramic piezoelectrics. She served MRS as a chair of the 2003 MRS Fall Meeting, a symposium organizer, and a guest editor of MRS Bulletin, and she was the 2011 chair of the MRS Planning Committee.

\title{
Black, Comini, Frey, Kiick, Tsakalakos to chair 2013 MRS Fall Meeting
}

\author{
www.mrs.org/fall2013
}

T he 2013 Materials Research Society Fall Meeting in Boston, December 1-6, will be chaired by Charles T. Black (Brookhaven National Labo-

\section{MRS} ratory), Elisabetta Comini (Università di Brescia), Gitti L. Frey (Technion-Israel Institute of Technology), Kristi L. Kiick (University of Delaware), and Loucas Tsakala- kos (General Electric-Global Research Center). Updated information on the meeting is available at www.mrs.org/ fall2013.

Charles T. Black is a Scientist and the Group Leader for Electronic Nanomaterials in the Center for Functional Nanomaterials, a US Department of Energy
User Facility at Brookhaven National Laboratory. His research interests include using nanostructured materials and self-assembly approaches in photo-

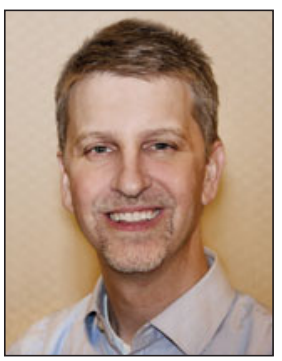
voltaic devices Black received his BS degrees in physics and mathematics from Vanderbilt University (1991) and his $\mathrm{PhD}$ degree in physics from Harvard University (1996). From 1996 to 2006, Black was a Research Staff Member at the IBM 
Thomas J. Watson Research Center in Yorktown Heights, N.Y. He has authored more than 75 publications and conference proceedings, and four chapters of books. He currently holds 37 US patents. Black is a Fellow of the American Physical Society and Senior Member of the Institute of Electrical and Electronics Engineers.

Elisabetta Comini is responsible for the research line on "Metal oxide nanocrystalline quasi-1D structures" in the SENSOR Laboratory at the University

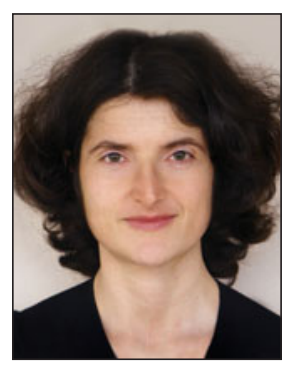

of Brescia and CNR-IDASC, in Italy. She is a research specialist in the growth of metal oxides, particularly nanowires, thin films and the measurement of their electronic, functional, and structural properties. She earned her Laurea degree in physics from the University of Pisa (1996) and her $\mathrm{PhD}$ degree in materials science from the University of Brescia (2001). Comini serves as a reviewer for various international journals and she is part of the technical program committee of several conferences in chemical sensing. She is supervising several undergraduate as well as graduate students at the University of Brescia. Comini has over 180 technical publications in peerreviewed journals, book chapters, and review papers; her $h$-index is 33 (ISI web of knowledge); she is also editor of various books and holds four patents.

Gitti L. Frey is an associate professor of Materials Science and Engineering at the Technion-Israel Institute of Technology. She received her BS and MSc degrees in chemistry with honors from the Hebrew University of Jerusalem, and her $\mathrm{PhD}$ degree in materials science from the Weizmann Institute of Science, Israel.
She served as a postdoctoral fellow in the Optoelectronics Group of the Cavendish Laboratory, at Cambridge University, then joined the Technion in the fall of

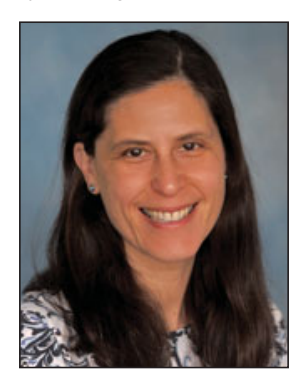
2002 where she was promoted to Associate Professor in January 2009. From 2009 to 2010 , she was a Visiting Professor at the Colorado School of Mines and Visiting Scientist in the National Renewable Energy Laboratory, Colorado. Frey's group has performed significant work in the field of functional hybrid materials, including the co-assembly of organic and inorganic precursors into hierarchical structures, and correlating the interfacial structure with photo-physical processes toward energy applications such as photovoltaics and light-emitting diodes. Among other awards, Frey received the Marie Curie Fellowship, The Alon Fellowship, and the Technion's Excellence in Teaching and Promotion of Research Awards.

Kristi L. Kiick is a Professor of Materials Science and Engineering and a Professor of Biomedical Engineering at the University of Delaware (UD), and has

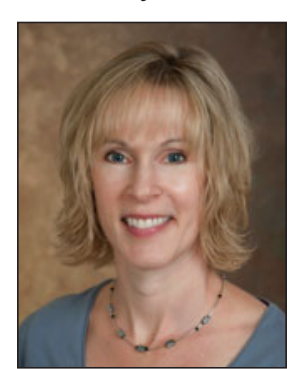
recently been named Deputy Dean of the UD College of Engineering. She received a $\mathrm{BS}$ degree from the University of Delaware, and an MS degree as an NSF Predoctoral Fellow from the University of Georgia. After working in industry at Kimberly Clark Corporation, she returned to academia for her $\mathrm{PhD}$ degree in polymer science and engineering from the University of Massachusetts Amherst, which she received in 2001. Kiick's research interests are centered on the use of biologically derived methods for the synthesis and assembly of advanced macromolecular materials with long-term applications in medicine and/or device technologies. Kiick has recently been named a Fellow of the American Institute of Medical and Biological Engineering. Her editorial activities include serving as a Principal Founding Editor for MRS Communications. She has authored or co-authored over 75 peer-reviewed papers and holds 15 US patents. She serves as the advisor of the MRS Student Chapter at UD.

Loucas Tsakalakos is a Senior Scientist at the General Electric (GE)-Global Research Center in Niskayuna, N.Y., and has recently been named Manager

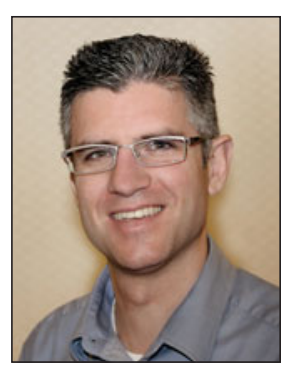
of the Photonics Laboratory. He received his $\mathrm{BS}$ degree (1995) from Rutgers University, and his MS (1998) and $\mathrm{PhD}$ (2000) degrees in materials science and engineering from the University of California-Berkeley. His expertise is in the integration of heterogeneous thin film and nanostructured materials systems for micro- and nanodevice applications, and he also has extensive experience in the characterization of materials. He is a member of Tau Beta Pi (The National Engineering Honor Society); the author or co-author of over 30 journals, conference proceedings, and book chapter publications, as well as over 30 internal GE publications; he has edited one book (on the topic of nanotechnology for photovoltaics) and holds 12 US patents. Tsakalakos is an associate editor of the Journal of Photonics for Energy, and has given over 30 invited presentations at various international conferences, workshops, and institutions. 